\section{Toekomstperspectief}

De regionale organisaties zullen flinke budgetten krijgen om de zorg in de eerste lijn beter te organiseren en aan te passen aan de behoeften van de verschillende groepen patiënten. Die behoeften bestaan bij veel patiënten in de eerste lijn niet alleen uit medische zorgverlening, maar ook uit maatschappelijke ondersteuning, vaak in combinatie. Een patiënt bij de huisarts is tegelijkertijd een inwoner van een gemeente met recht op maatschappelijke ondersteuning. De coördinatie tussen de medische zorgverlening en maatschappelijke ondersteuning kan mogelijk georganiseerd worden door die regionale organisaties. De gemeente kan dit stimuleren door mee te financieren, bijvoorbeeld met een bedrag per inwoner. Dat is in het belang van de patiënten met gecombineerde zorgbehoeften en biedt de gemeente de mogelijkheid om mee te sturen in de nieuwe eerstelijnsorganisaties - een eenvoudige manier om schotten te doorbreken.

Open Access This article is distributed under the terms of the Creative Commons Attribution 4.0 International License (http://creativecommons.org/licenses/by/4.0/), which permits unrestricted use, distribution, and reproduction in any medium, provided you give appropriate credit to the original author(s) and the source, provide a link to the Creative Commons license, and indicate if changes were made.

\section{Literatuur}

1. Nyst E. Bruins bezoekt huisarts Jung in Afferden. 2018. https://www.medischcontact.nl/nieuws/laatste-nieuws/ artikel/bruins-bezoekt-huisarts-jung-in-afferden.htm (Gecreëerd: 22 jun 2018), Med Contact.

\title{
Voorkomen is beter, maar ook lastig!
}

\section{Anja Koornstra}

Published online: 14 February 2019

(C) The Author(s) 2019

Preventieve zorg - het lijkt een contradictio in terminis. Preventie gaat toch voor de zorg uit? Maar tegelijk weten we dat zorgverleners vaak een heel goede relatie met hun patiënten/cliënten hebben en dat ze weten wat medisch gezien nodig is om het (verder) ontwikkelen van ziekte te voorkomen. Ook weten we dat de meeste patiënten/cliënten van zorgverleners juist verwachten dat ze zich ermee bemoeien. 'De dokter zegt niets van mijn overgewicht/roken/..., dus het valt nog wel mee.' En toch komt preventie in de zorg nog maar beperkt tot stand. Aldien Poll heeft een prachtig overzicht gemaakt van de mogelijkheden om in de (eerste-

\footnotetext{
A. Koornstra ( $\bowtie)$

GGD GHOR Nederland, Utrecht, Nederland

akoornstra@ggdghor.nl
}

lijns)zorg preventie een plek te geven. Zijn deze mogelijkheden voldoende?

\section{Basis}

Poll geeft aan dat er al mogelijkheden zijn om preventieve zorg te bieden, onder meer via specifieke programma's, zoals stoppen met roken. Desgevraagd blijkt dat stoppen-met-rokenprogramma minder dan 15.000 keer per jaar bij de zorgverzekeraars te worden gedeclareerd! Terwijl we weten dat in Nederland elk jaar circa 1 miljoen keer een stoppoging wordt ondernomen. Het complete en evidence-based programma lijkt dus maar nauwelijks te worden gebruikt. Daarom maak ik me ook zorgen over de mate waarin de Gecombineerde Leefstijlinterventie (GLI), die sinds dit jaar kan worden aangeboden, zal worden benut. Ik 
denk dat er drie aspecten zijn die nog aandacht behoeven, die ook benoemd zijn in de Agenda voor de Zorg [1], en die kunnen helpen om draagvlak te vinden voor oplossingen. Het gaat om aandacht voor preventie in de opleidingen, preventiebeleid in de zorgorganisaties zelf en prikkels voor preventie in de financiering.

\section{Willen is nog geen weten}

In de scholing is er gelukkig steeds meer aandacht voor preventie. Maar dat kan nog beter en dan vooral ook in de vorm van een grotere samenhang tussen universele, selectieve en geïndiceerde preventie. De kanteling richting preventie vergt kennis over de factoren die met gezondheid - meer dan ziekte - samenhangen en over de effectiviteit van preventie. Het is nodig om de inzet in preventie te professionaliseren. Beroepsorganisaties, opleiders en zorgfinanciers kunnen de kwaliteit van preventieve zorg verbeteren, bijvoorbeeld door goed lesmateriaal te (laten) maken en door te eisen dat preventieve zorg in de basisen vervolgopleidingen wordt ingebed. Ik pleit ervoor deze scholing en professionalisering samen met de publieke gezondheidszorg, zoals de GGD, op te pakken, zodat de werkvelden en de mensen elkaar verder leren kennen en integraal leren werken.

\section{Weten is nog geen kunnen}

Wat voor alle gedrag geldt, geldt ook voor zorgverleners zelf. Iedereen weet wat gezond is, maar er zijn duizend redenen om niet gezonder te gaan leven. Zo is het ook lastig om preventiever te gaan zorgen: het is druk, er is geen vraag, er is geen aanbod voorhanden, er is te weinig vertrouwen in de effectiviteit, het declareren verloopt omslachtig, het aanspreken van de patiënt kan misschien tot een minder goede vertrouwensrelatie leiden, enzovoort. En ondertussen neemt de werkstress alleen maar toe. Gedragsverandering heeft daarom inbedding nodig in het beleid van de zorgorganisatie en moet ook vertaald worden naar afspraken tussen werkgevers en werknemers: er moet ruimte zijn om preventie toe te passen. Het gaat daarbij ook over de zorgmedewerkers zelf, over de eigen gezonde omgeving en gezond gedrag. Ook hier pleit ik voor samenwerken tussen curatieve en publieke zorg, en ook de care: het Preventieakkoord kan een kans bieden om in alle regio's met zorgorganisaties af te spreken wat zij doen om gezondheid te bevorderen, niet alleen bij hun patiënten/cliënten, maar ook bij hun werknemers.

\section{Kunnen is nog geen doen}

In onze wereld zijn er veel prikkels om juist niet tot preventie over te gaan. Allereerst is het de cultuurnorm je zo min mogelijk te bemoeien met het leven van anderen. We zijn ontwend hoe je iemand kan laten weten dat je er bent, dat die ander gezien wordt, en dat je weliswaar alles zelf moet doen, maar niet per se alléén. Dit denken leidt ertoe dat in werk- en financieringsprocessen preventie op z'n zachtst gezegd niet wordt bevorderd. Deze denkwijze is alleen te keren door prikkels tot preventie in de reguliere zorg te bouwen. Om te beginnen door bij patiënten/cliënten actief aan te geven dat preventie kán: een Stoptoberstressballetje op je tafel maakt al zichtbaar dat jij er bent om te helpen bij gezond gedrag. Maar dat is niet genoeg. Ook in de financiering van zorg moet preventie duidelijker worden benoemd. Dat kan bijvoorbeeld in afspraken over omvang, wijze en effecten van uitvoering van preventie. Hierbij pleit ik wederom voor samenwerken met gemeentelijke diensten zoals GGD'en en sociale teams - we zien daar al mooie voorbeelden van [2]. Vaak wordt voor de financiering het Preventiefonds genoemd, maar ook andere financieringsvormen zijn denkbaar.

Zonder bovenstaande versterkingen vrees ik dat de GLI hetzelfde lot ondergaat als het Stoppen-met-rokenprogramma: effectief, maar in homeopathische hoeveelheden in het zorgsysteem toegediend, en dan blijft preventie een kwestie van geloven.

Open Access This article is distributed under the terms of the Creative Commons Attribution 4.0 International License (http://creativecommons.org/licenses/by/4.0/), which permits unrestricted use, distribution, and reproduction in any medium, provided you give appropriate credit to the original author(s) and the source, provide a link to the Creative Commons license, and indicate if changes were made.

\section{Literatuur}

1. Skipr-redactie. Steek energie in verbeteren van zorg, niet in systeemverandering. 2017. https://www.skipr.nl/actueel/ id29876-steek-energie-in-verbeteren-van-zorg-niet-insysteemverandering.html (Gecreëerd: $20 \mathrm{mrt} 2017$ ).

2. NHG. Preventie in de buurt. 2018. https://www.nhg.org/ preventieindebuurt. 